\title{
Informal interactions in 3D education: Citizenship participation and assessment of virtual urban proposals
}

\author{
David Fonseca ${ }^{\text {a, }}$ \\ fonsi@salle.url.edu \\ Francesc Valls ${ }^{\mathrm{b}}$ \\ f.valls@upc.edu \\ Ernest Redondo \\ ernesto.redondo@upc.edu \\ Sergi Villagrasa ${ }^{\mathrm{a}}$ \\ sergiv@salle.url.edu
}

'La Salle Barcelona Campus, Ramon Llull University, Barcelona, Spain

'Expressió Gràfica Arquitectònica I, Universitat Politècnica de Catalunya, Barcelona, Spain

Corresponding author at: La Salle Barcelona Campus, Ramon Llull University, C/

Quatre Camins 2, 08022 Barcelona, Spain. Tel.: +34 932902430.

\begin{abstract}
The main focus of this study was the inclusion of informal methods in the educational frameworks of architectural and urban design. The project used is based on the 3D representation of virtual models of new urban proposals in order to re-organize a local market in Tonalá, Mexico. Starting from a formal course, where the students had to develop solutions to real architecture and urban problems, a second phase was designed, based on feedback in an informal environment by the end-users (citizens and professionals). The key objectives of the experiment were to show students to connect and receive feedback through technology, evaluate how these interactions can define new informal ways of learning, and discuss how this informal data can be incorporated into an academic curriculum. The results confirm how the informal interaction constitutes a great contribution in the improvement of student's skills, even considering that the incorporation of informal data into their evaluation still remains challenging.
\end{abstract}

Keywords: Formal and informal learning; 3D education; Urban planning;Academic motivation; User experience; Qualitative assessment

\section{Introduction}

Information Technology (IT) represents a set of tools and applications that allow the incorporation and strengthening of new educational strategies, many of which have 
been defined in new teaching frameworks in the last two decades (Dede, 2000). In recent years, the use of ITs has spread to all levels of our society. The affordability of prices and the popularity of devices and applications have enabled its ubiquitous presence in leisure, relationships, work activities and of course teaching. The adaptation of contents and applications in this area has emerged as an interesting field of study to assess the degree of motivation, satisfaction and usability of students (Redondo, Sánchez, Fonseca \& Navarro, 2014), and their academic improvement (Fonseca, Martí, Redondo, Navarro \& Sánchez, 2014). To evaluate these premises, the standard approach is to start from formal educational approaches and quantitative studies, but as has been recently demonstrated (Fonseca, Redondo \& Villagrasa, 2014), qualitative approaches are equally valid and allow a more accurate characterization of the teaching experiences, especially when these involve IT.

On the other hand, informal learning is a potential tool to evaluate the citizens' response and is typically associated with other fields of science, technology, engineering, and mathematics (STEM) education (Gray, Nicosia, \& Jordan, 2012; Mueller, Tippins, \& Bryan, 2012), and a basic skill to be developed specially in the education of future urban planners, architects, or building engineers. The importance of informal learning lies in the fact that $70 \%$ of a person's learning is done informally, either at work or at school (Marsick, Watkins, Callahan, \& Volpe, 2006). While the veracity of this rule can be discussed, it cannot be disputed that the designs of architects, urban or building engineers will be used by the citizens, and the citizens' response and evaluation will be essential to develop successful projects and proposals. As students'progress from high school to college and graduate schools, the role of informal learning becomes increasingly important because learning can happen anywhere at any time (a key concept in the learning process of architecture students, because architecture is everywhere). As Banks et al. (2007) propose, our students acquire knowledge as a result of interactions between connected partners.

New technology implementations in the teaching field have been largelyextended to all types of levels and educational frameworks. In recent years, in addition to technology use in the classroom, new areas of research are opened to assess and recognize more effective and satisfactory teaching methods, such as: gamification strategies, Project Based Learning (PBL), Scenario Centered Curriculum (SCC), and the recognition of capabilities that provide the non-formal and informal education. The use of IT in learning methods, especially at the level of graduate or postgraduate degrees in frameworks related to Architecture, Urban Planning and Design, or Building Engineering, is defined in the new academic plans. It is important that the student 
should be able to get competencies and skills related to active and collaborative learning, and digital information management, all of them using roles and PBL exercises. All of these methods are prepared for a quicker and more effective capacitation of the student compared to classic educational methods.

For all these reasons, it is necessary to propose new educational methods that complete the actual PBL and SCC systems, increasing the student motivation, and their involvement and performance. The interest of educators in using these technologies in the teaching process supposes greater engagement and an increase in the students comprehension of content (Kreijns, Acker, Vermeulen, \& Buuren, 2013; Roca \& Gagné, 2008; Shen, Liu, \& Wang, 2013), leading to an improvement in academic results.

Not until recently, research has begun to quantify the huge impacts of informal experiences outside the classroom on motivation and achievement. Architecture, Civil and Urban design education should not be solely located in a closed environment (classrooms), but just the opposite, it should also take place outside the classroom on the streets, squares, etc. (Medeiros, 2011). In these open places knowledge is often built via collaboration, and people act as learners and teachers alike (Bell \& et al., 2009). Recognizing that learning occurs across such a wide range of settings can lead to new significance to such simple and everyday actions as a walking to the bus stop, a jog in the park, or even a conversation over dinner, because in all these situations the architecture and/or design is around the student. Given this understanding, landscape architects, civil and building engineers or urban designers have a particularly interesting and exciting responsibility to help the public become interested, informed, and fascinated with their proposals (Scheerens, 2009).

We can affirm that in the last years, more attention has been given to the idea of active participation of communities and individuals (the end-users) in the development of policies, programs or proposals that affect their lives (Foroughi, 2013; Fung \& Wright, 2003; Hall \& Clover, 2005; Schugurensky, 2004). As will be discussed further in the paper, a successful informal learning space is a topic in need of further research, but especially useful for a student, as in our case, who will be in direct contact with the needs of today's society, and therefore needs to improve his or her training exploring the behavior of end users.

The present study has two main objectives. First, we analyze the implementation process, the difficulties of use, and the degree of students'satisfaction when using an advanced visualization technology with personal mobile devices - we proposed the use of Virtual and Augmented Reality (VR/AR) and Digital Sketching using Hybrid Models 
(DS/HM). Secondly, we will investigate the informal data from end-users, who have interacted with the 3D student's proposals and will discuss if the proposals of the students have been designed successfully. We will employ a qualitative analysis to obtain the most relevant aspects of the experience that should be improved both in future interactions of students, architects or engineers, and in any new technological implementations within a teaching framework. Analyzing the results of these objectives will lead to a better understanding of how to implement new teaching methods with mobile technologies and how to manage hybrid approaches between formal and informal education in our educational sector.

\section{Literature review}

\subsection{Informal education: citizenship role in architecture, building or urban design}

The User eXperience (UX), and the usability of a product or project have been handled normally as tools for testing the quality of every utility or system (Nielsen, 2012). Based on the results that the product obtained of the interaction with end-users, developers get valuable information. This feedback allows a better adjustment, redesigning and improving a system based on the opinion and typology of the endusers. Historically this process has been used in the design of web environments, consumer products such as appliances and all kinds of technology, especially those related to areas such as leisure and social relations (Nielsen, 2000). However we can affirm that it has great potential if adapted appropriately to education, since based on the behavior and emotions of end-users of a proposal, the designers of those (students) may improve in future projects.

Usually most studies are designed in a regulated manner, i.e. within an educational environment and a formal student training. However, in recent decades, there have been studies and research that emphasize the importance of other forms of education away from schools, regardless of the level (Harrop \& Turpin, 2013; Jamieson, Dane, \& Lippman, 2005; La Belle, 1982). Learning processes are not only confined in regulated areas but also non-formal or informal ways are present throughout a person's lifetime. To do so initially we must clearly differentiate between all types of education currently defined (Coombs, Prosser, \& Ahmed, 1973):

Formal education: Learning typically provided by an education or a training institution, structured and leading to certification. Formal learning is intentional from the learner's perspective: the hierarchically-structured, chronologicallygraded 'education system', running from primary school through university and 
including, in addition to general academic studies, a variety of specialized programs and institution for full-time technical and professional training.

Non formal: Any organized educational activity outside the established formal system-either operating separately or as an important feature of some broader activity - that is intended to serve identifiable learning users and learning objectives.

Informal: Learning resulting from daily life activities related to work, family or leisure. It is not structured (in terms of learning objectives, learning time or learning support) and typically does not lead to certification. In this case, each individual acquires attitudes, values, skills and knowledge from daily experience and the educational influence and resources in his or her environment.

In base of these definitions, the architectural education allows incorporating (in a complementary way) non-formal educational elements, such as specialized courses, as well as informal education. In the education of a future architect or of a similar profession (such as a building engineer, civil engineer, or interior designer), the acquisition of knowledge informally is vital, because the development of a professional project always has a huge influence based on experience. Along this line, one of the great forgotten issues in urban design has been the project perception of the end-users (Fraser \& Miss, 2012). This review not only determines the success or failure of a project, but also informally influences the education of both future architects and active professionals (Bilandzic, 2013; Hawkinson, 2013; Rios, 2014).

It would be difficult to compile the number of functional projects based on their design that have become architectural failures or that have generated controversy once finished (Benévolo, 1997; Frampton, 1981; Pampinella, 2000). As listed below, not even the great architects and their works have been free of bad user experiences, from structural problems or other minor problems that affect the end-user. The perception and assimilation of criticism continues to be an example of informal education, better or worse incorporated into new professional projects (Schugurensky \& Myers, 2008). We have new interesting opportunities based on informal civic democracy to engage both students and citizens in the design of our new society's cities and urban projects:

7 buildings with structural problems that cause problems in the environment or in its habitability (Taylor-Foster, 2013). 
Examples of dangerous constructions for users and/or with building problems (Luna Corento, 2013):

Constitution Bridge, Venice and Zubizuri Bridge, Bilbao. Santiago Calatrava.

City of Culture, Santiago de Compostela, Peter Eisenman

Nous Encants, Barcelona, Fermín Vázquez

Farnsworth House, Mies van der Rohe. This weekend retreat was never inhabited apart from the budget problems between client and architect; it is remarkable due to environmental comfort issues (Craven, 2013).

Ville Savoye, Le Corbusier (Bobhate, 2011). From the onset of its construction, the building had severe problems with the weather, both from water and wind, being widely documented in the correspondence between the residents and the architect (Al Shawa, 2011; Sully, 2009).

Paving tiles in Paseo de Gracia, Terradas Architects. The design of the new pavement meets aesthetic, a comprehensive study of materials and their adaptation to the Mediterranean climate, but has also been criticized for its roughness and possible problems that can cause treading with heels (Mateos \& Quelart, 2014).

Olympic Stadium, Montreal. Roger Taillibert. This building is famous because its cost (more than 20 years to be paid, Wright, 1978), and its structural problems (in study its possible demolition because its underuse, Roult \& Lefebvre, 2010), being initially a groundbreaking building with the tallest inclined tower in the world (Lazzari, Majowiecki, Vitaliani, \& Saetta, 2009).

The disease of modern buildings: the semicircular lipoatrophy. Referenced and related buildings for the first time in 1974 (Gschwandtner \& Münzberger, 1974; Romanillos, 2007). 
As Biggs proposed (1999), the evaluation and control of the quality of education and development of students is a key concept in the implementation of technologies in classrooms: teaching and assessment practices must be aligned with the aims of teaching. In this sense one of the most standardized examples of aligned teaching is the work using SCC and PBL, which in fields of Civil, Urban and Building engineering, where the project is restricted as explained in this paper, are perfectly suited. However, the experience shows a high rate of very subjective assessments (same project for different architect or end-user can switch seamlessly to failure). For this reason, it is common to find courses and professionals very reluctant to implement self-evaluative systems and/or clarify the evaluation of Teaching/Learning Activities (TLAs), as well as to take into account the opinion of the citizenship in their proposals (one of the main reasons why informal learning in our educational field is being difficult to incorporate). The justification of a subjective evaluation system is based on the negative effects that explicit quantitative assessment have on the student, where this can be spent to follow a strategy that will help students not to pass but to learn. It is not the only case of some difficulties in the integration of informal learning in the schedule of the subjects (Werquin, 2008), there are other factors as for example the response time of the users, the relevance, the validity of the responses, etc.

In conclusion, it seems to be clear the need to incorporate an informal approach to education of areas whose projects are to be used by the public is essential. The views of users are not only basic but provide information that the student should be able to assimilate in their education to improve the acquisition of skills and competencies described in their academic plans. However, as we will later see it is not an easy task, and the results need a complicated and time consuming process of interpretation which impairs effective incorporation into semi-evaluation processes currently used.

\subsection{New learning strategies: Good practices and SCC}

Designing an educational experiment does not always work successfully. Involving new technologies and the use of multiple devices is not always synonym of an effective user experience (Rodriguez-Izquierdo, 2010; Fonseca, Redondo, \& Villagrasa, 2014). A good design to motivate and improve students'learning can be transformed into just the opposite. Any "Good Educational Practice" must have different parameters for monitoring and evaluating each exercise, environment and student (Fonseca, Martí, Redondo, Navarro, \& Sánchez, 2014). And on the opposite side there is the students' work. As a practical exercise it can perfectly meet all evaluable and pre-established criteria in technology and performance, but it would be necessary to check whether the proposal is also functional and usable (Sánchez, 
Redondo \& Fonseca, 2012). This is an essential step which is usually forgotten in the teaching faculties, mainly due to lack of time (Fonseca, Villagrasa, Valls, Redondo, Climent \& Vicent, 2014), and in which we focus our case study.

The interest, necessity, and urgency of implementing new technologies in education and universities is a relatively new situation (Rogers, 2000). However, technological innovation, which is intended to improve the student learning process, must be capable of providing support to address difficulties that could arise with the student in the use of and interaction with technological elements. These elements must not obstruct the auto-learning process, which is altered by this technology, and the students must be motivated with the new educational methodology. It is not unusual for the faculty to be the first line of resistance against technological innovations in teaching. There is a natural reticence in the academic field about the use of technologies that are associated with leisure or personal relationships, such as mobile devices (Fonseca Redondo \& Villagrasa, 2014).

Another major deterrent to implementing IT in teaching is the administrative environment: professors must be trained (Georgina \& Olson, 2007) and must be capable of giving full-time support to students, the success of which is dependent on the professors' willingness and ability to devote the time required for the training, modification, and update of the related content. To incorporate a new IT-based methodology into a specific teaching environment, some recommendations for avoiding student rejection must be considered. The literature defines so-called "good educational practices" that are primarily focused on virtual rooms, distance education (or elearning), and semi-present teaching (Moreira, Santos \& Vargas, 2010). From the specific characteristics that shape these practices, four points can be extrapolated, as indicated by the following principal objectives:

Promotion of professor-student relationships: More effective feedback process.

Dynamic development among students: Collaborative techniques.

Contribution to better task realization by heterogeneous learning methods.

Applying teaching/learning methods based on teaching innovation and new IT technologies. 
According to different authors (Massy \& Zemsky, 1995; Phang \& Kankanhalli, 2008), any methodology that promotes the inclusion of IT in teaching must have the following objectives, based on four main categories (social, cultural and personal aids):

Personal production help: applications that allow both the professors and students to carry out tasks faster and more efficiently (i.e., calculation sheets or text processers, draw programs).

Content improvement: the use of tools that allow for the notification and modification of content rapidly and efficiently (i.e., e-mail, digital content, video, multimedia resources) without changing the basic teaching method.

Paradigm change: at this level, the teacher reconfigures the teaching activity and learning activities to utilize the new incorporated technologies and methodologies to improve the educational tasks.

Examples of educational methodologies that have implemented the two first objectives are common, but examples that incorporate the third objective are much less common. In this direction, we can find examples that are incorporating quite successful teaching strategies based on SCC, game design for task tracking (also known as gamification) and taking into account courses and activities that could encompass as non-formal or informal tasks.

In contrast to traditional programs (passive and focused on subject matter) a SCC offers an experience equivalent to learning a trade: learners must face a wellplanned series of real situations (scenarios) in a significant and motivating role. Within these scenarios, they must carry out precisely those tasks, activities and reasoning processes that are best suited for building the desired skills (Higueras, 2013). This way, learners facing a problem on their own notice why certain skills are useful. This type of program is the most common exercise that the civil and building engineering students are doing using a PBL system. The SCC are defined as the following:

Scenario: Simulation of an authentic situation that can motivate providing a coherent context for individual and collective learning.

Sequence of planned tasks. Framed within the scenario, this allows the student to practice the key behaviors targeted in the training and, as a result, learn them. 
Structured suite of complementary learning resources: This includes work procedures, models to be used, job aids, workplace tools, glossaries, etc.

Access to a mentor: Online or in person, to obtain feedback and help precisely when it is necessary to reinforce learning.

In civil engineering, urban design and construction education, students are accustomed to using SCC and PBL strategies in the learning process. However the 3D visualization and comprehension are skills and abilities which are marked in their learning, where virtual and environmental systems are being the ones that are showing better adaptation to such content. Additionally, we can find studies that have reflected the role of gamification and game-based learning (as a sub-model of PBL) in assessment within virtual environments (Wood, Teräs, \& Reiners, 2013), an example of systems that can improve the assessment while increasing efficiency and providing new opportunities for educators to use motivation and ubiquitous systems (Villagrasa, Fonseca, \& Durán, 2014).

The combination of 3D models with urban information (specifically when this information can be viewed and managed ubiquitously) will allow students the acquisition of skills related to historical knowledge, project development, and urban planning. Future architects and planners should be able to manage the SCC proposed from early stages, since in this particular field it is very difficult to work with abstractions and simplified models. The use of ICTs in education has the clear objective to promote an enhanced learning (TEL), which in multiple forms (assistance and semiassistance), generates on one hand much more motivation and academic improvement of students and on the other hand teachers have greater ease of monitoring and evaluation. Literature on use of explicit, pedagogical strategies dedicated to enhance creative problem solving is relatively scarce (Retalis \& Sloep, 2011).

Thus, there is an open research and development issue on learning strategies that could effectively promote creativity and innovation. The design-oriented pedagogy for TEL (for example using exercises based on PBL) allows the students using collaborative environments to create and discuss new spatial proposals, improving both general and specific skills in the border of formal and informal educational environments Learning to collaborate and connect through technology is an essential skill that future societies will expect from its people (Binkley et al., 2011). 


\subsection{Information technologies: Enhancing the student motivation and new assessment methods}

\subsubsection{Mobile learning and education}

Mobile Learning (ML), early works addressed from a scientific point of view are COMTEXT (Kristoffersen \& Ljungberg, 1999), understood as a virtual environment for learning using mobile devices. Other experiences (Lehner \& Nosekabel, 2002), extend the same idea in a virtual university based on the use of Internet and mobile devices, by developing a ML platform called WELcome. However we could simplify its definition as one of the new learning strategies that is based on the use of mobile devices in education, profiting from their graphical power, applications and connectivity. These devices and their applications are what allows us to say that we are in front of the new sketchbooks, because due to their increasing usability and resolution we are able to draw freehanded (Fig. 1).

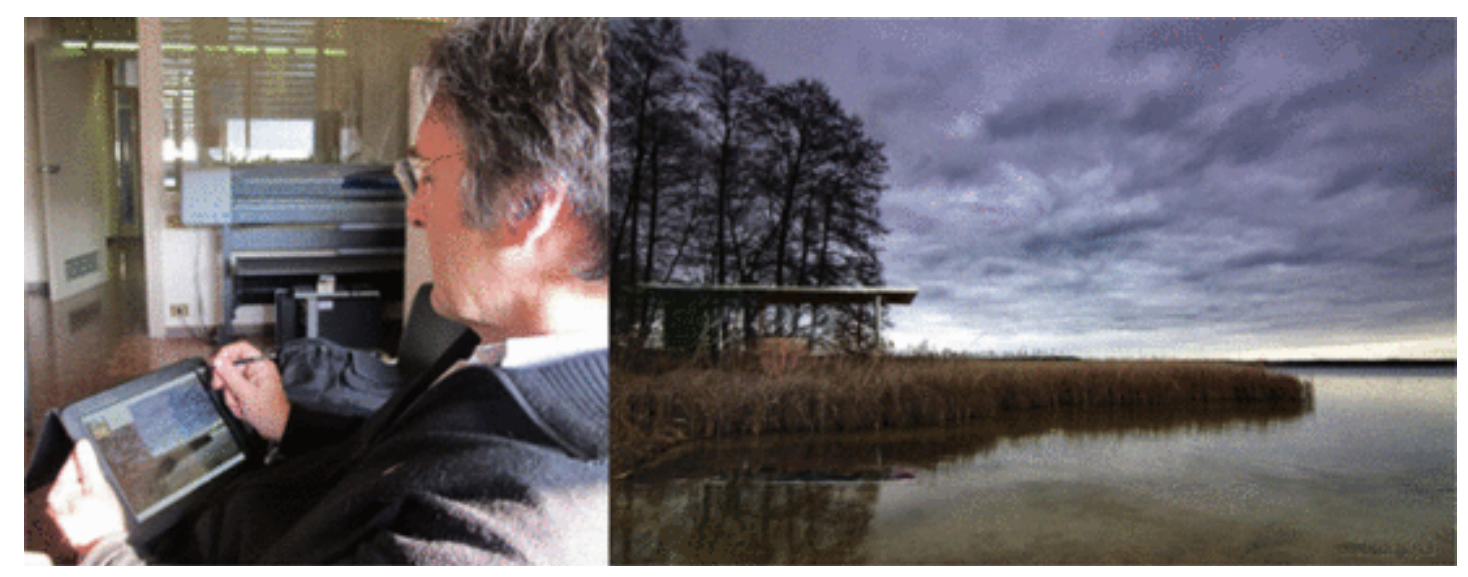

Fig. 1 Digital Sketching using tablet-pc.

Moreover, promoting offsite collaborative work, students using mobile devices such as smartphones or tablets have greater capability not only to share and exchange their work between them and with their teachers, but also to search and access all kinds of support information much more quickly, making the sketching activity, the continuous self-learning and the contextual training, a more enriching experience than the classic system of lectures.

The evolution of mobile technologies and the increased power and sophistication of mobile phones, which have led to the advent of smartphones and tablets in the last ten years, have created a new body of research on the use and optimization of these devices in ubiquitous training, allowing for both onsite and virtual collaborative work with faculty members and students (Lu, 2012; Parsons, 2012). The increasingly advanced but easy-to-navigate applications directly generate a greater utility perception from the user and a better attitude about using this technology (Kuo \& 
Yen, 2009); these premises represent one starting point for a more consistent inclusion of these technologies in teaching.

We can define the generic ML concept, with the following principal characteristics: the interaction between the user and content, the contribution of media to immersive environments, the incorporation of communication technologies, the use of new contexts for education, and the awareness that sharing and recording the process of learning is possible. This definition includes technology because it involves the provision of collaborative tools, such as blogs and wikis (Moran, Seaman, \& TintiKane, 2011), mobile-device interactions (e.g., iPhones, Android mobile phones, Wiis, iPods), new virtual simulation training environments (e.g., Second Life, VR, AR), and connectivity tools for searching locations (e.g., 2D codes, Google Maps).

The collaborative training tools between teachers and students can be strengthened when they use familiar technological resources where students can demonstrate their receptiveness. The integration of mobile devices with multimedia applications provides students with immediate access to information (unlike traditional methods) and expands their experience beyond the academic environment.

\subsubsection{Digital Sketching: the new travelogue of architects}

We can define the Digital Sketching (DS), as those drawn on mobile devices using pointers or gestures that mimic traditional techniques and require the same skills than traditional freehand drawing (Fig. 2) (Redondo, 2010). These methods and systems support many more editing possibilities and make easier to share the work on the network, especially if compared to traditional travel sketchbooks. The union of these devices with the specific characteristics of digital drawing allows us to affirm that we are in front of the natural evolution of said travel sketchbooks and the on-site sketches or the sketches in the early stages of the project, which represent a large qualitative leap in the advance of architectural drawing.
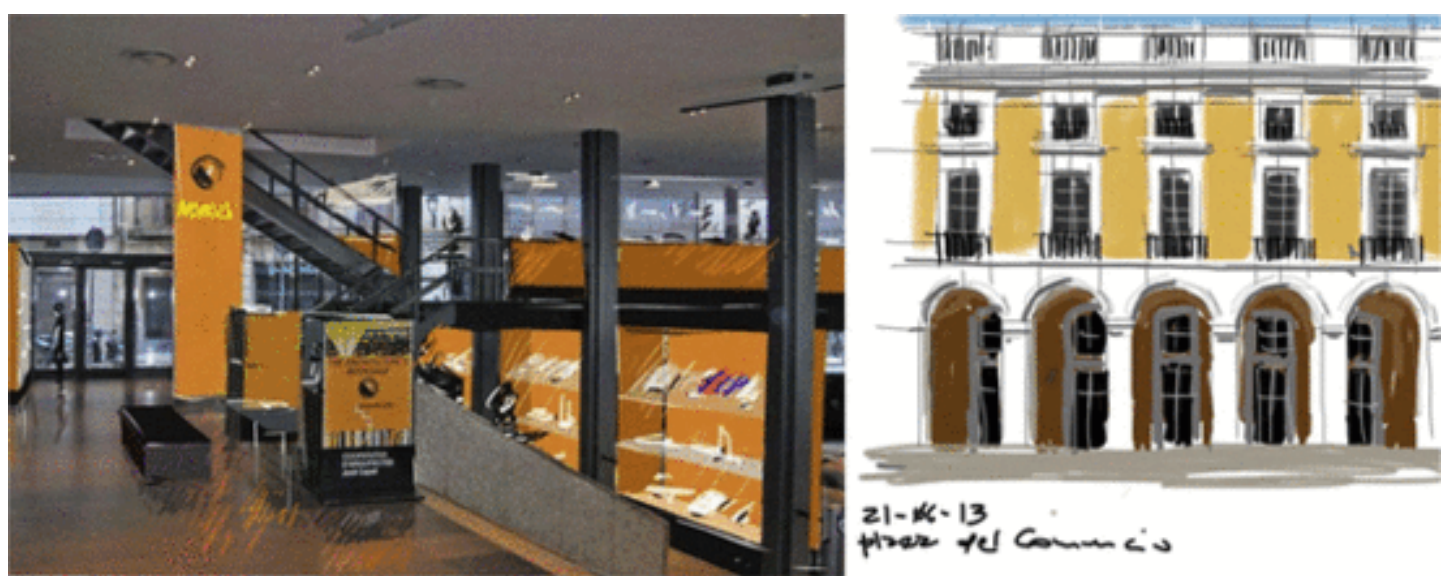

Fig. 2 Examples of Digital Sketching using mobile devices. 
In this direction, and based on several previous experiences in architectural teaching (Redondo \& Santana, 2010), it has been shown that this type of drawing over digital interactive boards is a suitable tool for the teaching of traditional drawing and that its use in combination with IT improves the graphics skills and the students' academic performance. Generalizing the working definition, it could be said that we are in front of a hybrid drawing technique, and could be defined as the work with files in different formats that are juxtaposed in the same representational level. Another way to define these systems would be that they are the methods through which a drawing or graphic can be generated using elements of different nature, or what is the same, strategies and methodologies where perception and geometry, art and technique, manual and mechanical are blended. In short, the artistic and technical-geometrical components are put together in as single system, not juxtaposed but sharing the same digital platform (Fig 3).

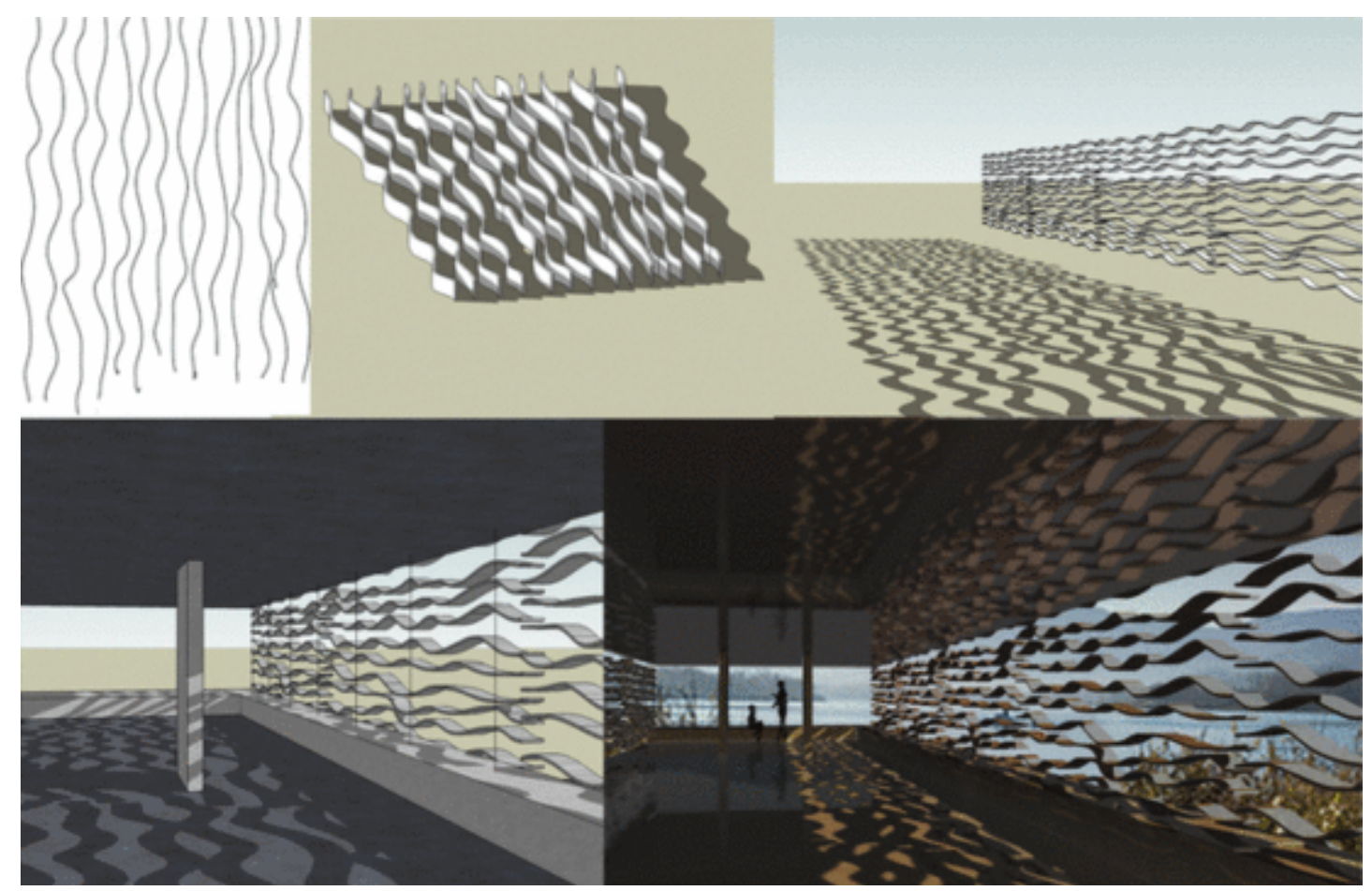

Fig. 3 Examples on Hybrid models and representation.

While the various groups of tools discussed give support to all kinds of problems in any environment, hybrid drawings have mainly focused on solving the representation of architectural designs (Leggitt, 2009; Uddin, 1999; Yaman, 2009). Thanks to this clear approach we can say that in view of the weakness in the perceptual training of students and their natural acceptance of computer resources (Bennett, Maton, \& Kervin, 2008; Prensky, 2001), these systems can be a helpful shortcut in their training and spatial comprehension. Likewise, it is clear that hybrid approaches applied on 
teaching strategies, especially when related to graphical topics, can be a solution to both improve students'motivation and ease their learning process.

\subsubsection{Hybrid visualization methods: from VR to AR}

One visualization technology that is gaining attention and is being incorporated into every field is Augmented Reality (AR). Its creators (Milgram \& Takemura, 1994) define AR as a VR variation in which the user can see the real world with virtual objects mixed or superimposed upon it. In contrast to VR, AR does not replace the real environment; rather, AR uses the real environment as a background. AR and VR share common features, including immersion, navigation, and interaction (Dunleavy, Dede, \& Mitchell, 2008). However, AR has two main advantages over VR. First, AR allows for collaborative experiences in a real scene: users can work with computer-generated objects as if they were real objects in a real environment, in real time. Second, AR allows for tangible interactions: by superimposing virtual objects onto a real environment through markers, the user can modify and manipulate the scale, position, and location of virtual objects. AR technology, by providing new interaction possibilities, promotes active student participation in its own knowledge construction.

This concrete superposition capability between virtual models and reality makes this technology an interesting resource in any type of teaching in which improving students' spatial comprehension may be required. In education, however, AR might be considered a new tool, and further studies are necessary, with particular attention paid to the user experience and learning process. Concretely, the entertainment capability of these technologies can increase interest in less interesting classes, including classes in which the content is presented with no interaction with the student, which could lead to demotivation and loss of interest (Chen \& Wang, 2008; Di Serio, Ibáñez, \& Kloos, 2012).

One of the main objectives of the present study is performed within the context of the use of AR in architecture and urban design instruction to improve students' spatial comprehension, a topic that few studies have investigated (Broll et al., 2004; Malawi \& Srinivasan, 2004; Piekarski \& Thomas, 2001; Tonn, Petzold, Bimber, Grundhöfer, \& Donath, 2008). The integration must be accurate and at the right scale to achieve the hypothetical situation and size matching in an actual scene. If a student can control these parameters and avoid possible mistakes, he/she will achieve an improvement in spatial capacity for analyzing any type of architectural figure using a familiar technology, such as his/her own mobile device (e.g., laptop or telephone) and can work collaboratively in knowledge creation and generation with his/her classmates and the faculty. At this point the importance of evaluation that students receive by 
citizens and their proposals arises. And this view is especially important since they will be users who interact with the proposals in the event that these are implemented, and therefore use, or suffer the generated design.

In architectural education, the visual component is one of the more relevant aspects that a student works and studies with (Boeykens, Santana-Quintero, \& Neuckermans, 2008). Spatial information is represented in a number of ways, ranging from traditional methods, such as printed plans and physical models (working from 2D to $3 \mathrm{D})$, to modern methods, which we call as "hybrid" since they are designed with the aim of visualize in the most optimal way any architectural or urban proposal.

Focusing on the specific case of AR, and the introduction of this technology in different areas of the architectural education framework, is easy find examples in design, excavation, staking, inspection, coordination, urbanism, landscape design, rehabilitation, tourism and supervision of tasks (Hawkinson, 2013; Shin \& Dunston, 2008; Sánchez \& Borro, 2007; Tonn et al., 2008). New platforms and paradigms emerged to propel AR development in smartphones, such as Junaio, Layar and Wikitude, all of them in order to improve potential problems. All of these companies embraced a new concept that consisted in creating AR browsers with a number of features that allowed developers to produce AR content according to a specific set of rules and, finally, enabled end-users to view computer generated elements superimposed on the live camera view of common smartphones. These AR browsers are compatible with most mobile operating systems, such as Android, the iOS, or Symbian.

A framework in which this technology could potentially be used in more interesting ways is the representation and management of territory, because real scenes could be "completed" with virtual information. This method would facilitate a greater awareness and better understanding of the environment, especially if used in the architectural educational framework, for example with the visualization of $3 \mathrm{D}$ complex models (Redondo, Sánchez, Fonseca,_\& Peredo,_2013; Redondo, Fonseca, Sánchez \& Navarro, 2014).

\section{Case of study}

\subsection{Location and project design}

The city of Tonalá is located a few kilometers from Guadalajara, Mexico. It is an urban area whose traditional activity has always been the industry and handcraft of pottery and its street markets. These street markets are commonly known as "Tianguis"; the most famous one takes place on Sundays and Wednesdays because of its size and the variety of products sold. This market chaotically occupies much of the streets of the 
city. The Municipality of Tonalá is trying to regulate these markets and at the same time trying to improve the infrastructure of the city, with special emphasis on the sidewalks and signage of their streets.

As we can see in Fig. 4, the aim of these objectives is not only to improve the urban landscape but also remove architectural barriers. Citizen participation in these processes are not common and a challenge in our particular case. The city of Tonalá has neither previous experience in UX projects nor a high level of implementation of advanced devices for mobile visualization and interaction. In this case, in addition to the evaluation of the use of IT in the design phase and the visualization of new proposals in an education environment, we aimed to harness the structure of the University of Guadalajara to engage students and faculty of the Tonalá High Schools, as well as professionals of architecture and urbanism, and at the same time local merchants in the evaluation process of the students proposals for an informal feedback.
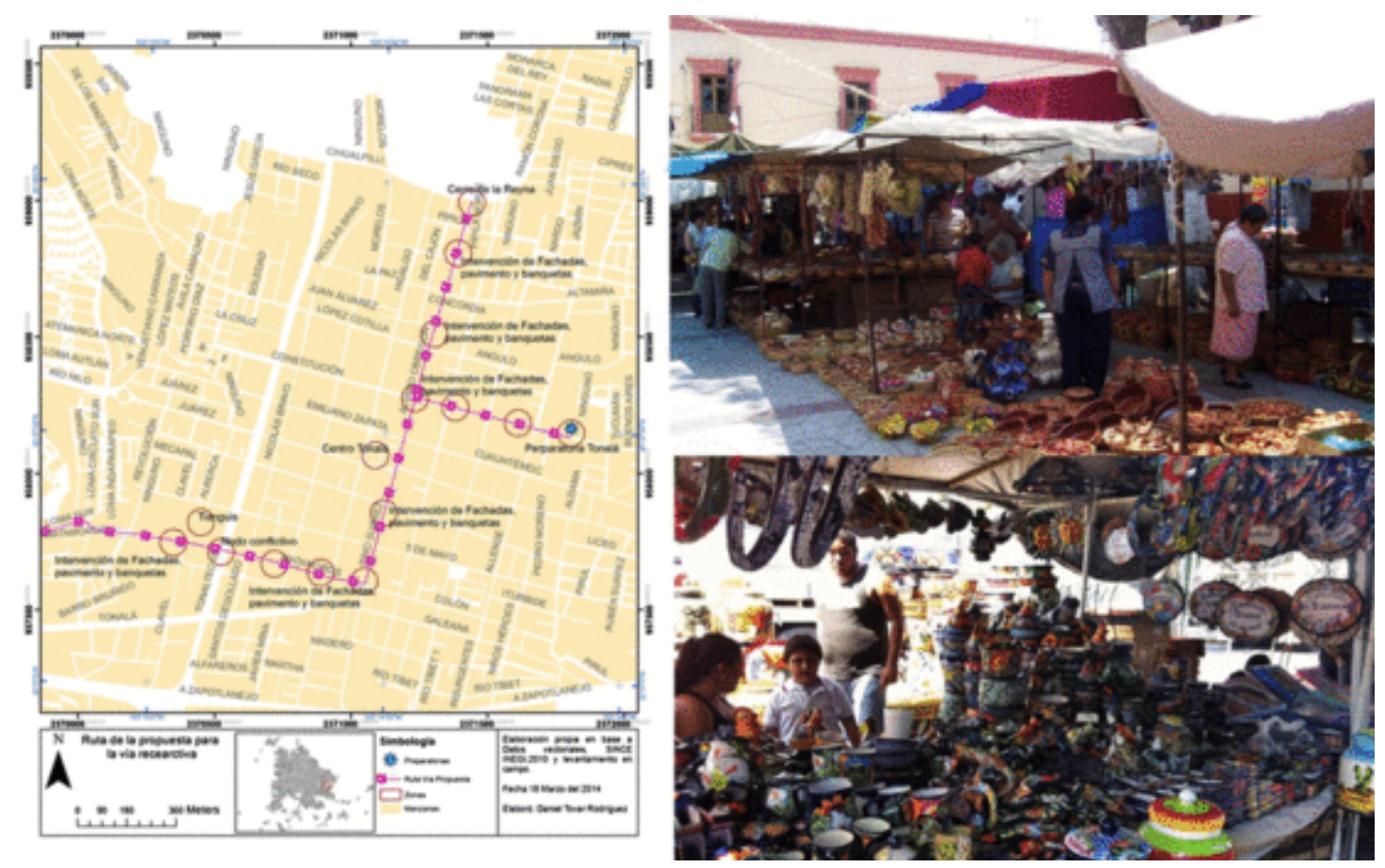

Fig. 4 Tianguis location in Tonalá. Urban-rehabilitation project.

The PBL is designed from two distinct approaches: the completion of a formal exercise and informal evaluation of the proposal by users. By performing the proposed PBL, students not only have been evaluated according to their acquisition of skills and competencies but first approached the review of their work by their future end users (the society in which they will project), as pre-established main objective.

The formal exercise is designed for inclusion in the workshop "Computer Systems applied to the Graphic Analysis of Architecture" (from 24 h February 2014), and was developed in the Master in Processes and Graphic Expression of the Urban and 
Architectural Project of the CUAAD (Centro Universitario de Arte, Arquitectura y Diseño, CUAAD) of the University of Guadalajara in Jalisco, México. The main objective that this workshop developed was the following: initial evaluation of the technological profile of the student. The objective was to evaluate the real possibility of exercising, (because it is necessary that students have both the technology, time and motivation necessary for a successful experience). In order to achieve this, we have designed two phases:

Basic exercises using AR: This phase is intended to train students in all necessary techniques, allowing them to coordinate and display the $3 \mathrm{D}$ models in real space contexts.

Qualitative evaluation on the use of AR (using the Bipolar Laddering Assessment, BLA, which we will discuss in the next section).

In addition to the informal evaluation of proposals, explanatory posters were positioned in the location corresponding to the position developed. Thus, users with available camera devices have been able to visualize and evaluate qualitatively AR models such proposals. In the results section will discuss in more detail this part of the project. The data presented in this informal stage is still preliminary. While it did already provide as discussed below useful information for students, the goal is to continue until mid-2015 to get the most responses. We must recall that citizens use the QR (Quick Response) that allows the evaluation of proposals in their location (the QR links to a survey with questions related to AR and the student proposals).

The initial workshop is part of the first phase (formal education), and had these following objectives: modeling new street furniture (points of sale of the"Tianguis"), reorganization of the streets and their new urban design using DS through digital drawing on tablets, and conducting the evaluation and visualization of proposals using $\mathrm{AR}$ and VR-Objects over mobile devices. VR-Objects and interactive panoramas are representations generated by juxtaposition of multiple renders that make up a SkyCube or SkyDome. They are managed by a HTML file, in the first case creating a panoramic view around the observer, and in the second orbiting around a point. These files are downloaded into a smartphone or tablet, in addition to being orbited with a finger, leveraging the capabilities of the accelerometers to simulate the rotation of the viewer in a real setting (in our case incorporated in the virtual model as circular panoramic image in PNG format). 
The first part of the workshop consisted on a 5-h session where the subject and the work system was presented, initial surveys about the students profiles were conducted, and the project site was visited. In the second session, with the guidance of tutorials and the lecturer, the different technologies that would be used (DS and AR) were explained and tested using mobile devices (smartphones and tablets, both Android and iOS) using markers or geo-referenced positioning. In the third session, groups of two were defined that had to propose the design of a new hawker stand and the draft of a new paving and remodeling of the streets in the area of study. The fourth session was dedicated to export the virtual models to the AR applications and the geo-referenced interactive panoramas created with VR-Objects, testing the visualization of all elements in the CUAAD premises. Notably, since the models were not fully developed in the initial phase, they lacked definition about their structural framework or massing, but were useful as a first visualization approach (Fig. 5). The last session was dedicated to the public, presentation of the results and the final survey using BLA methodology.
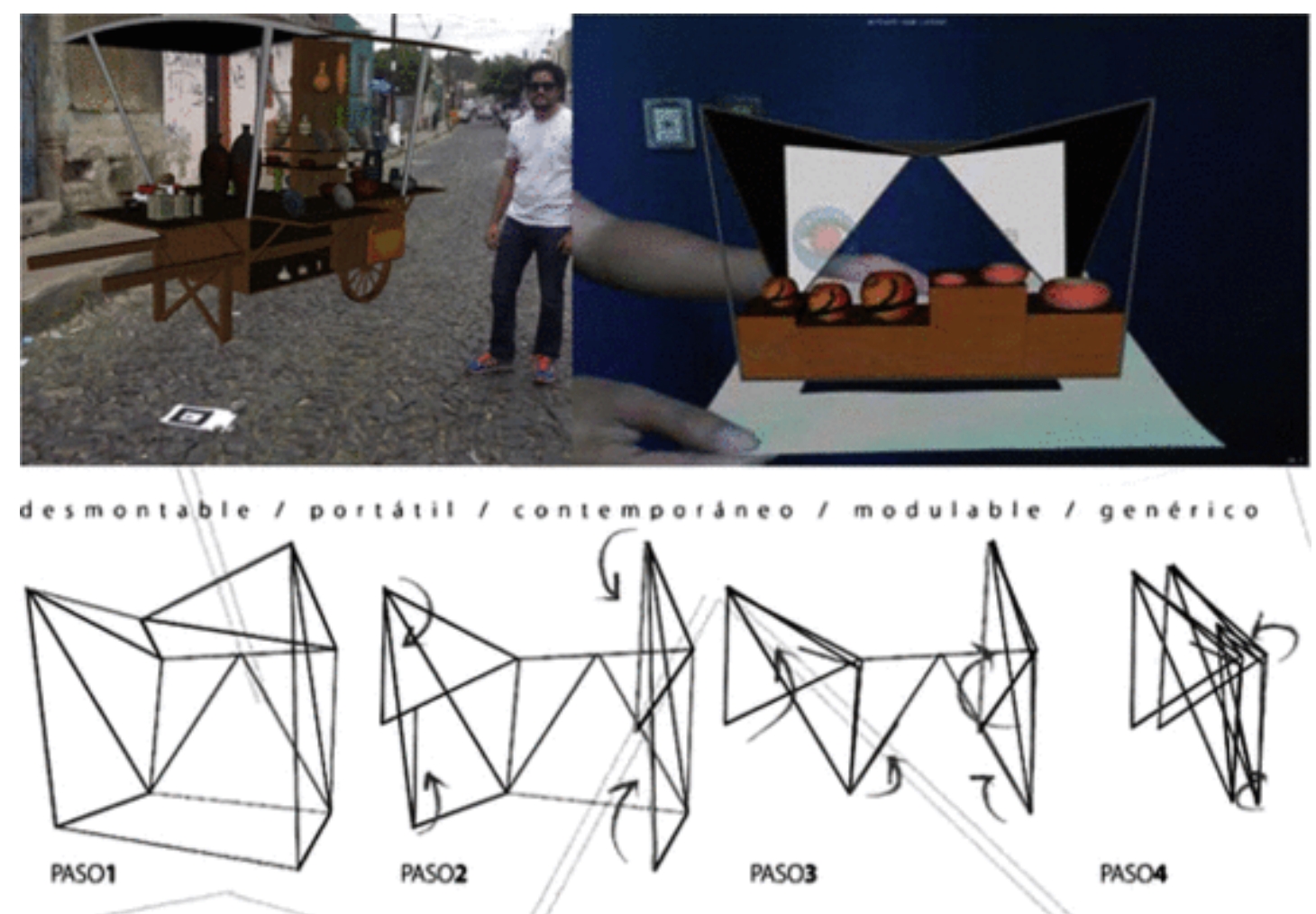

Fig. 5 Test of prototypes visualization using AR.

For the proposal, the objects/images were generated in Artlantis and its visualization configuration was done with iVisit 3D Builder. After this steps, by placing the files as a shared resource using Dropbox, the users could download the files in their devices to visualize them with the iVisit 3D Player. One of the main features of the viewer is that it allows to geo-reference the panorama according to its heading, and 
download it with a QR core in its precise location, facilitating a better understanding of the model.

The AR visualization tests were carried out with the AR-media Plugin for SketchUp and its viewer ARplayer, both for Android and iOS devices. The generation of interactive panoramas and VR-Objects were done from the educational version of Artlantis and the export module iVisit 3D Builder to be able to visualize the models in the iVisit 3D application for Android and iOS (Fig. 6).

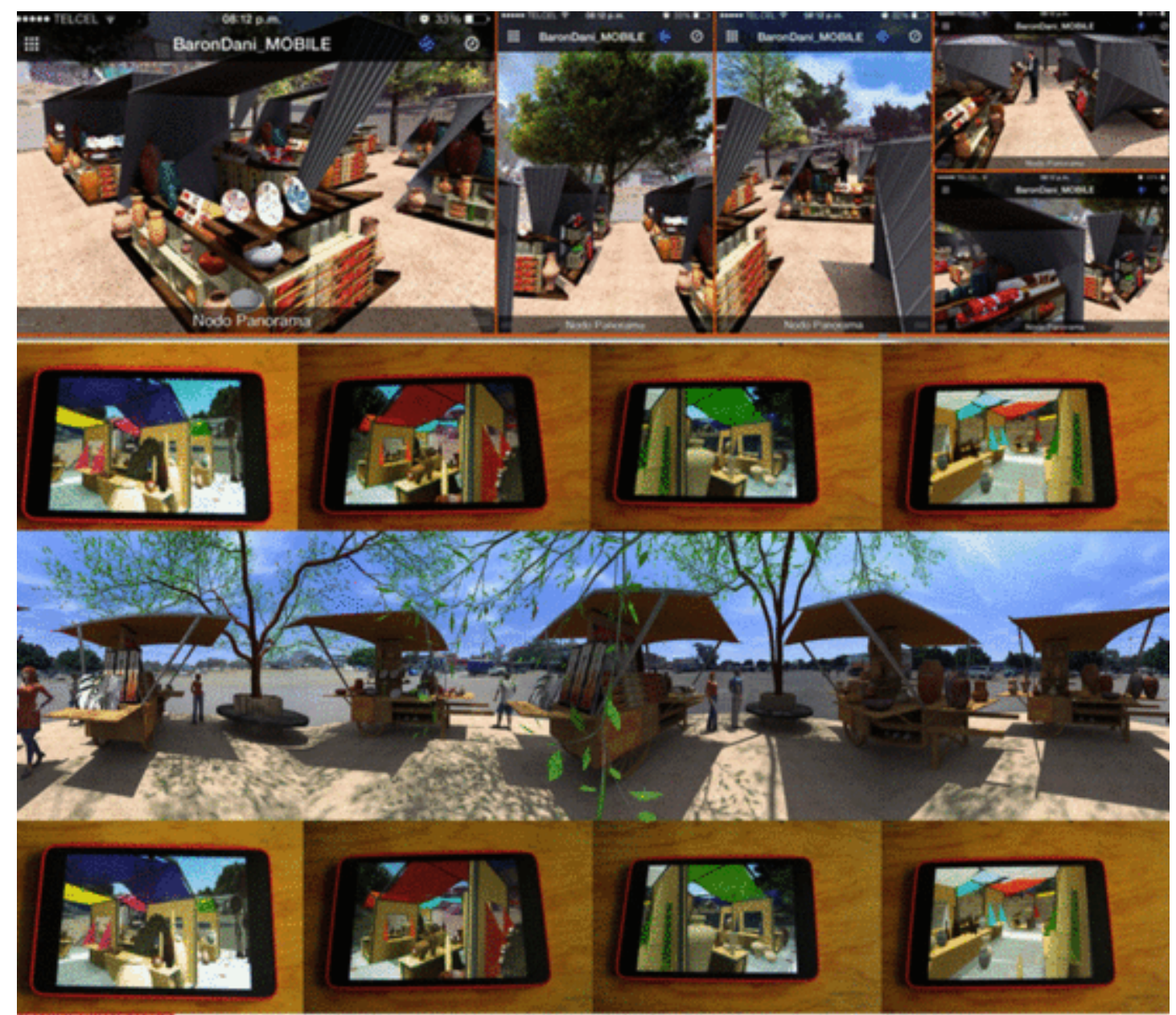

Fig. 6 Process of generation of interactive panoramas ready for mobile devices.

On the other hand, the DS application used was the educational version of SketchBook on iPad 2 tablets (see examples in Fig. 7). The final presentation of the course was the creation of a panel, triptych or report that explained the urban design project and point of sale proposal that at the same time described the creative process. For this purpose, the students had to illustrate their work and the design process through DS, AR and VR-Objects, including an explanation of the process. All the information had to be stored in a link identified with a QR code. 


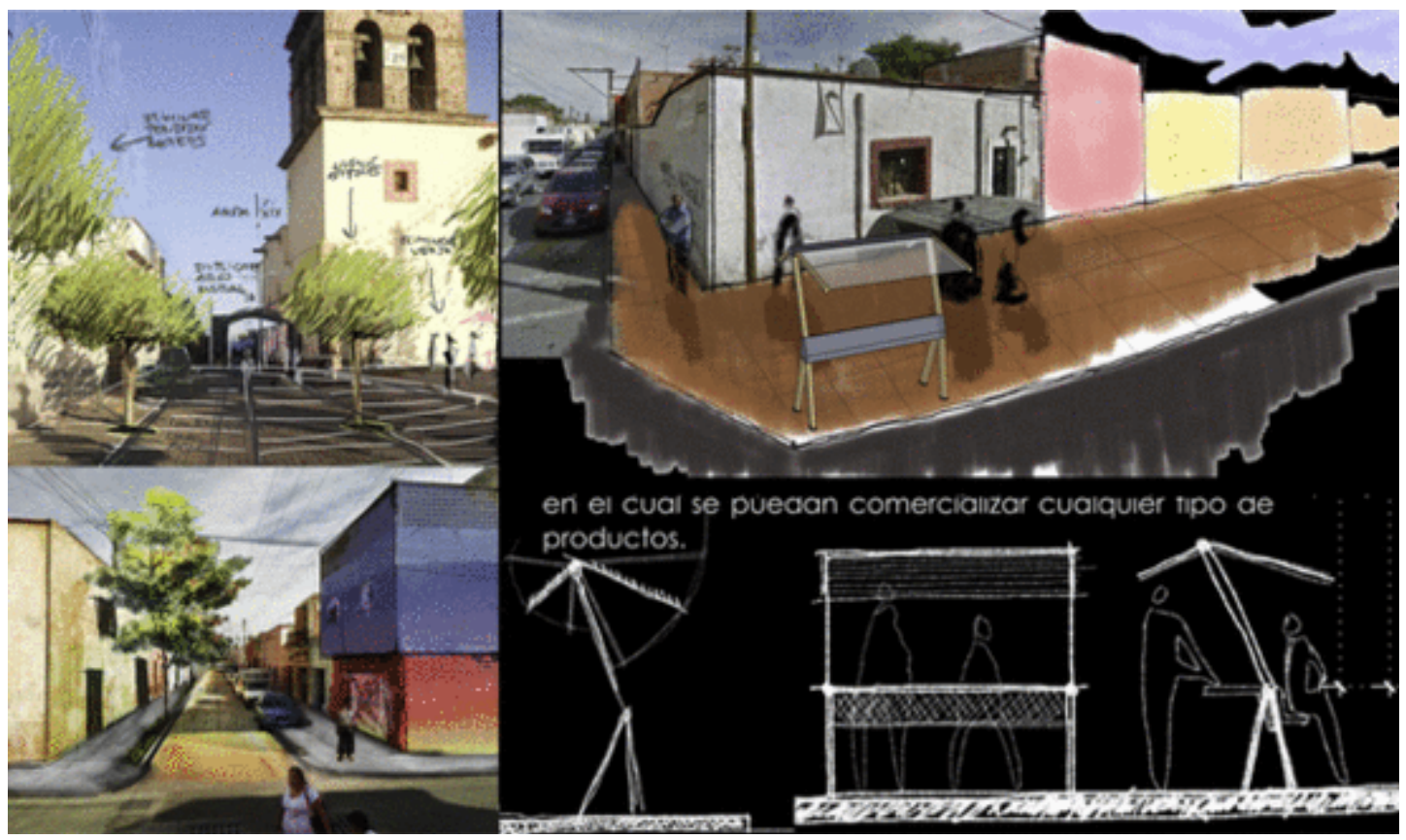

Fig. 7 DS in mobile devices.

Educational evaluation is certainly a field in continuous development and constant new proposals. Based on the initial user profile survey results, and given the availability of students' use of tablets during the course (at least one per group), these devices allowed study sketches, intuitive photomontages and freehand sketches on the project site. The purpose of this work was to assess the substitution of the traditional travel notebooks with mobile devices capable to fulfill these needs. Of the 30 students of the group, 27 got a passing grade and 4 of them passed with honors because they were able to generate all the work requested, with good architectural quality and presentation.

\subsection{Educational assessment: qualitative formal and informal approach}

As previously stated, one of the key issues in the current university teaching is the management of student motivation. The change in the educational systems of the past decade (which involved a reduction in the number of hours of teaching classes), along with a reduction in the number of university students has caused a shift in the teaching paradigm, currently focused on how to improve the ability and skills of the students.

The proposal presented in this article, evaluation is if anything even more complex, as we aim to involve three distinct approaches: The Teachers evaluation (formal education). In this field, we are migrating from traditional systems based on tests to testing new models that assess the degree of acquisition of competencies and 
skills described in each case. The evaluation through rubrics and their adaptation to the student tracking systems are currently a challenge regarding their implementation.

The evaluation of the technological proposals and their adaptation to students (UX study). For any given assessment of both technological or not, discussions arise whether the best approach is quantitative work, qualitative or mixed (which fuses both), the generation of statistical analysis of responses, indicators, correlation studies, etc.

The evaluation of the end-uses (informal feedback). The study by SCC and PBL generates a huge amount of subjective and difficult to parameterize information, but nevertheless provides a quality assessment on the work done by the student.

In our case, as we have stated previously, we propose the use of AR and DS as working platforms and presentation of planning proposals. To this objective we will design various assessment tasks in order to parameterize the experience at the highest level possible. This process is necessary for future iterations to more clearly define in a teaching methodology that integrates formal and informal aspects. Initially students will do a quantitative test to assess their technological profile. After the practical part, we have generated rubrics for teacher evaluation, a qualitative test for the evaluation of the usability of the technology used, and finally (and in order to incorporate the informal evaluation of the project), we have interviewed a number of random users about whether their valuations affect the educational experience of students, but in the case of this first proposal without being quantified formally.

Qualitative methods have been traditionally linked to the social sciences because of their association with human factors and user experience (UX). User research techniques have been historically related to the Human-Computer Interaction. The user approach in this discipline is mainly focused on the study of behavioral goals in work settings. In consequence, the task becomes the pivotal point of user-centered analysis and evaluation techniques (e.g. usability testing). The qualitative studies are inspired by experimental psychology and the hypothetical-deductive paradigm, and employ samples of users who are relatively limited.

Nevertheless, the Socratic paradigm from postmodern psychology is also applicable and useful in these usability studies because it targets details related to the UX with high reliability and uncovers subtle information about the product or technology studied (Pifarré \& Tomico, 2007). This migration from the hypotheticaldeductive paradigm to the Socratic paradigm was inspired by the paradigm shift in 
clinical psychology away from constructivism and toward other post-modern schools of psychotherapy. This psychological model defends the subjective treatment of the user, unlike the objective hypothetical-deductive model (Guidano, 1989).

Starting from the Socratic paradigm basis, the BLA system (Bipolar Laddering) has been designed. BLA method could be defined as a psychological exploration technique, which points out the key factors of user experience. The main goal of this system is to ascertain which concrete characteristic of the product entails users' frustration, confidence or gratitude (between many others). The BLA method works on positive and negative poles to define the strengths and weaknesses of the product. Once the element is obtained the laddering technique is going to be applied to define the relevant details of the product.

The object of a laddering interview is to uncover how product attributes, usage consequences, and personal values are linked in a person's mind. The characteristics obtained through laddering application will define what specific factors make consider an element as strength or as a weakness. BLA performing consists in three steps:

Elicitation of the elements: The implementation of the test starts from a blank template for the positive elements (strengths) and another exactly the same for the negative elements (weaknesses).

Marking of elements: Once the list of positive and negative elements is completed, the interviewer will ask the user to mark each one from 0 (lowest possible level of satisfaction) to 10 (maximum level of satisfaction).

Elements definition: The interviewer reads out the elements of both lists to the user and asks for a justification of each one of the elements performing laddering technique. Why is it a positive element? Why this mark?

Once the element has been defined, the interviewer asks to the user for a solution of the problem he just describes in the case of negative elements or an improvement in the case of positive elements.

For informal assessment of citizenship, which is performed independently from the link via QR code generated by the panels and / or from personal interviews with tutors of the project, the following three questions where:

Do you think that the RA is useful? 
On basis of the difficulty of using what could it be used for?

Rate the proposed Tiangui displayed.

The questions are designed to assess the users' reaction to visual technology that had not been previously used. It also seeks to establish a relationship between the use of technology as a vehicle that allows a better expression of the proposals and urban designs. All this to conclude evaluating proposals from student's free-form. This aspect is key as end-users ignore formal compliance with the expectations set in the workshop, and simply assess directly whether proposals may or may not fulfill their ultimate goal: the redevelopment of the market. As we will see later, users have provided key information not considered in the design phase, which allows students to establish new design criteria that must be considered on future projects.

\section{Results}

\subsection{User profile and motivation}

A total of 15 students participated in the study ( 9 males and 6 females, mean age $=28.75$ years, $S D=7.01$ years). All students previously took drawing, design, and $2 \mathrm{D}$ and $3 \mathrm{D}$ modeling courses. At the beginning of the course, the students were asked to estimate their degree of knowledge, usability, and interest in technologies generally and specifically in the use of informatics devices and mobile technology, the Internet, and social networks. To design the pre-test, or technological profile test, a structured test was used with the Intranet Moodle system of the university. All of the questions were scored on a five-point Likert scale $(1=$ never or strongly disagree, $5=$ always or strongly agree). In addition, questions were formulated to obtain the degree of knowledge and expectations of using AR prior to the experiment. The basis of this form is found in previous studies that suggest that higher interaction, usage, or interest levels produce better learning effects . Additionally, demographic questions were asked, including age, gender, and grade.

The User Profile Test_provided a first approach to the main interests and the student's working style. We descriptively highlighted the following items: all students $(100 \%)$ connect online at home and at the university, mainly using laptops (100\%) and mobile devices (72.73\%). The connection types used are ADSL/Cable at home and university (100\%), and Wi-Fi (63.64\%). The most commonly used services are mainly e-mail (100\%), search engines (90.91\%), download services $(81.82 \%)$, and queries form blogs and social networks related with studies or professional services $(81,9 \%)$. A total 
of $91 \%$ of the students have a smartphone (compared to of $9 \%$ have a simple mobile phone with no multimedia applications), and these students are more accustomed to working on portable laptops (72.7\%) than on desktop computers (36.3\%). $54.5 \%$ of students have a tablet device.

We can resume the principal statistics obtained from the most directly related study questions (using a Likert scale of 5 points), that in general, the students are heavy technology consumers, both in usage and in interest. They perceive the incorporation of AR into architectural teaching as a complex tool $(M=2.58, S D=1.31)$, and the students lack clear forecasts of how can it affect, help, or improve the visualization and presentation of architectural projects. In the other hand, they are motivated in its use $(M=4.67, S D=0.90)$, and with the hypothesis of a great utility $(M=4.33, S D=1.07)$, very close of the traditional methods $(M=4.75, S D=0.62)$.

\subsection{Qualitative final assessment}

As stated previously, to evaluate the degree of adaptation to and satisfaction with the proposed method, as well as the advantages of working with a mixed system of data collection, students were invited to voluntarily participate in the study. For the qualitative study (using BLA), we randomly selected a balanced sample of 10 students (5 men and 5 women) who agreed to participate.

Studying the data collected using the BLA system (the final qualitative test), we will highlight the motivation of the students using new technologies in the visualization of architectural projects (MI: 40\%, Av: 9.50), the usefulness of the knowledge acquired and their application to real projects (MI: 50\%, Av: 9.00), and the usability of the proposed systems and especially the use of the "photomontage" as a creative tool (MI: $30 \%$, Av: 9.33). In short, the enhancements to the methods for presenting architectural projects should not be modified in the redesign process or further exercises (Table 1).

Table 1 Positive Common (PC) and Particular (PP) elements.

\begin{tabular}{|l|l|l|l|}
\hline \multicolumn{1}{|c|}{$\#$} & \multicolumn{1}{|c|}{ Description } & \multicolumn{1}{|c|}{ Av. score (Av) } & \multicolumn{1}{|c|}{ Mention index (MI) (\%) } \\
\hline 1PC & IT useful for real projects & 9.00 & 50 \\
\hline 2PC & Motivation using IT & 9.50 & 40 \\
\hline 3PC & Usability of photomontages & 9.33 & 30 \\
\hline 4PC & Usability of the applications & 8.67 & 30 \\
\hline 5PC & Quality of AR in final presentation & 8.50 & 20 \\
\hline 6PC & AR Uses & 8.00 & 20 \\
\hline
\end{tabular}




\begin{tabular}{|l|l|l|l|}
\hline$\#$ & \multicolumn{1}{|c|}{ Description } & \multicolumn{1}{|c|}{ Av. score (Av) } & \multicolumn{1}{|c|}{ Mention index (MI) (\%) } \\
\hline $1 \mathrm{PP}$ & Teachers & 10.00 & 10 \\
\hline $2 \mathrm{PP}$ & Usability of mobile devices & 9.00 & 10 \\
\hline $3 \mathrm{PP}$ & IT education & 9.00 & 10 \\
\hline $4 \mathrm{PP}$ & Digital drawing & 9.00 & 10 \\
\hline
\end{tabular}

In terms of the main negative comments, students clearly identified a lack of time in the first phase of explanation, identifying the need of more detailed tutorials in order to clarify the options of the applications used (MI: 40\%, Av: 3.75), and problems with the size of the group and the work in pairs (MI: 40\%, Av: 3.75), ideas discussed from the students because of they are more comfortable working individually and with the need for quick access to the faculty for questions (Table 2). Technically, these would be the main aspects to modify in future iterations of the proposed method: the creation of on-line tutorials to guide the explanation of the applications and reduce the student/teacher ratio with the possibility of working individually.

Table 2 Negative Common (NC) and Particular (NP) elements.

\begin{tabular}{|l|l|l|l|}
\hline \multicolumn{1}{|c|}{$\#$} & \multicolumn{1}{|c|}{ Description } & Av. & MI (\%) \\
\hline $1 \mathrm{NC}$ & Lack of time in the initial explanation & 4.00 & 40 \\
\hline $2 \mathrm{NC}$ & Workgroups & 3.75 & 40 \\
\hline $3 \mathrm{NC}$ & Accessibility to last generation hardware & 5.00 & 20 \\
\hline $4 \mathrm{NC}$ & More accessibility to software & 4.50 & 20 \\
\hline $5 \mathrm{NC}$ & Problems reading help files & 4.50 & 20 \\
\hline $1 \mathrm{NP}$ & Tutorials with low detail & 6.00 & 10 \\
\hline $2 \mathrm{NP}$ & More time to practice & 4.00 & 10 \\
\hline $3 \mathrm{NP}$ & Difficulties to read AR marks outside & 4.00 & 10 \\
\hline $4 \mathrm{NP}$ & Schedule of the workshop & 3.00 & 10 \\
\hline $5 \mathrm{NP}$ & Problems with the deadlines & 2.00 & 10 \\
\hline
\end{tabular}

Table 3 shows the features in proposals for improvements, both for positive and negative elements mentioned in the previous steps.

Table 3 Proposed Common Improvements (CI), and Particular Improvements (PI), for both positive and negative elements and for common and particular items.

\section{Description}




\begin{tabular}{|c|c|c|}
\hline & Description & Mention index (\%) \\
\hline $1 \mathrm{CI}$ & More time to practice & 80 \\
\hline $2 \mathrm{CI}$ & More time of previous explanation & 50 \\
\hline $3 \mathrm{CI}$ & Use better examples & 50 \\
\hline $4 \mathrm{CI}$ & More research about shadows & 40 \\
\hline $5 \mathrm{CI}$ & Use more devices & 30 \\
\hline $6 \mathrm{CI}$ & Explanation of more tools and APPs & 30 \\
\hline $7 \mathrm{CI}$ & Reduce the students by group & 30 \\
\hline $8 \mathrm{CI}$ & Offer loan service of equipment & 30 \\
\hline $9 \mathrm{CI}$ & Highlight key ideas & 30 \\
\hline $10 \mathrm{CI}$ & Define video/on-line tutorials & 20 \\
\hline $11 \mathrm{CI}$ & Improve the equipment of the classroom & 20 \\
\hline 1PI & Improve the student's following & 10 \\
\hline 2PI & Reduce the 3D explanation & 10 \\
\hline 3PI & More exercises & 10 \\
\hline 4PI & Annual Subject & 10 \\
\hline $5 \mathrm{PI}$ & More explanation of design concepts & 10 \\
\hline 6PI & More time in the exam & 10 \\
\hline 7PI & More teachers in the subject & 10 \\
\hline 8PI & Practice more simple & 10 \\
\hline
\end{tabular}

The lack of the integration of results and the study of their relationship, at this phase we can draw an important point that has reflected by the qualitative approach: the students do not reduce the investment of time (as we could expect, without the need of print or perform classical physical mock-ups), because they required more hours of explanation, practice and debugging to create the final projects.

\subsection{Informal citizenship feedback}

To evaluate the end-users' feedback based on their subjective criteria visualizing the student's proposals, a qualitative approach was used. The users were invited to voluntarily participate in the study and share their opinion. The first set of users who tested the display was composed of a total of 24 people. We have identified four main subgroups, users related to architecture (students and professionals N1: 6), 
commercials (N2: 4), workers with no architecture skills (N3: 7), students and teachers from high school (N4: 7). The most talked about aspects (positive and negative) mentioned (related to the first question of this survey) were:

Mention Index 45.83\% (+, positive aspect): Users who first saw operation of AR and were highly impressed. Highlights included citations of $71.4 \%$ of students and $57.1 \%$ of employed persons, and that none of the merchants in the market discussed the technology used.

$29.16 \%$ (-, negative aspect): The users understood that these proposal would be best suited to a wider environment (like a square) and for stationary use (static, without displacement). The mobile "tianguis"proposed do not adapt to the urbanization of Tonalá and produce serious problems of its installation and displacement. This has been cited by $75 \%$ of traders, reflecting the understanding of the problem as something close to their daily work. The other subgroups have cited this aspect below over-age, highlighting the $28.5 \%$ of students.

$29.16 \%(-)$ : Selection of materials used in the proposals was criticized, considering that the more traditional would be better adapted to the market rate, instead of other cutting edge materials. The group with a higher rate in this commentary was the people related to architecture (50\%).

$24.33 \%(+)$ : Users understood AR as a very useful and applicable technology in other areas especially on issues related to architecture, leisure, tourism and generally displaying heritage. In this section, the group that has commented on this aspect was those related to the field of architecture with a total of $33.3 \%$.

16.6\% (-): Little display space for products and / or too much unexploited volume. $75 \%$ of traders have criticized the proposals due to a reduction in the useful area of commercial stands compare to the current system, something that directly affects their operation.

The results indicate on one hand a high degree of uncertainty on the part of end users in the difficulty of use and global consensus on its usefulness. About $45 \%$ did not have a position on the difficulty of using the AR because they had not been used or worked with it before. The average perceived difficulty in the use of this technology is 
in an intermediate area (Av: 3.25, SD: 1.23), a result obtained from a scale from 5: user 1: high difficulty. However $100 \%$ believe the proposed work used by students as very useful, emphasizing as the most repeated comments those that positioned experience and technology as especially useful for:

Visualization and better understanding of architectural projects,

Improved cost in the project presentation phase to avoid costly models and printed presentations,

Educate the public and students in the use of interactive methods, which allows a better adaptation of the learning pace.

\subsection{Discussion}

The basic purposes of this study was to determine whether the use of friendly technology, such as mobile devices, and new interactive and collaborative methods to visualize architectural and urban models improves the motivation and academic performance of students based on formal practice and the informal data of the citizenship. The results indicate that AR is a good system to visualize both simple and complex 3D models. The experience was welcomed by the students, who appreciated using the new methodology applied to architecture education and especially if these types of exercises helped to improve their academic performance.

In the discussion of the proposed method, we evaluate the incorporation of AR in architecture and urban education based on three main variables: usefulness, level of improvement of project presentations, and difficulty of use. For this purpose, we compare the means of those variables in the pre-test (where all data are related to student perception with no knowledge of the technology) and the final assessment of the proposals by students and end-users (where the student had worked with AR and evaluates its performance, and the citizenship have interacted with the students proposals, Table 4).

Table 4 AR main method variables.

\begin{tabular}{|c|c|c|c|c|}
\hline \multirow[t]{2}{*}{ AR-variables } & \multirow{2}{*}{$\begin{array}{c}\text { PRE-test levels perceived } \\
\text { Mean }\end{array}$} & \multicolumn{3}{|c|}{ POST-assessment real levels } \\
\hline & & Students & Citizenship & Final average \\
\hline Useful & 4.33 & 4.50 & 5.00 & 4.75 \\
\hline Improv. Arq. project & 4.67 & 4.45 & 4.50 & 4.47 \\
\hline
\end{tabular}




\begin{tabular}{|l|l|l|l|l|}
\hline \multirow{2}{*}{ AR-variables } & \multicolumn{2}{|c|}{ PRE-test levels perceived } & \multicolumn{3}{|c|}{ POST-assessment real levels } \\
\cline { 2 - 5 } & Mean & Students & Citizenship & Final average \\
\hline Usability & 2.58 & 3.56 & 3.20 & 3.38 \\
\hline
\end{tabular}

Our findings show positive aspects: students evaluate AR as an easier to use technology $(M=3.56)$ than was initially expected $(M=2.91)$, which improved student participation and motivation as observed in the different academic sessions and led to an improvement in students' academic performance. Also, the level of Perceived utility $(M=4.75)$ and the results related to whether AR is a good system for architectural visualization $(M=4.47)$ were equivalents to the values obtained in the PRE-Test, and with a very high average which indicates that the proposed method and technological application tested generates high expectations for both professional users who developed (the students), and those who have used (citizens).

Other results that were extracted from the final interviews on the experience shows us some problems, or perhaps rather "information", both referring to the technological part of the proposals. We find problems related to the connection between technologies and formats. The need for various applications complicates the workflow and generates incompatibilities for proper allocation of materials and colors for effective visualization. Also, users have commented that 3D models shake excessively when displayed on mobile device screens, the model size is limited by the method of scaling within AR applications, and the small screen size of the devices (those situations are the main problems when observing small objects and architectural details).

The implemented case study, as a differential factor the similar case studies in the field of architectural design and teaching, provide the analysis of informal learning. Thanks to the information provided by end users who have evaluated the proposals of the students, we have identified a number of factors to change or improve to increase its functionality. However we have identified a number of limitations when implementing this type of informal interactions integrated into the curriculum of student: long time of evaluation, heterogeneous users, users' technological access problems and finally clarification of the most important aspects to evaluate in each proposal. These difficulties limit the integration of the informal education field for students of architecture or urban design, but certainly endorse the information obtained, highlighting the necessity to create new opportunities for the recognition of the role informal education today.

\section{Conclusions}


As mentioned initially, this study focused on three main objectives: to educate students to connect and receive feedback through technology, evaluate how these interactions can define a new informal way of learning, and discuss how this informal data can be incorporated into an academic curriculum. The selected proposal has focused on one of the most important aspects in the formation of architectural and town planning in order to assess these objectives: the visual presentation of proposals and the evaluation by end-users. Our Proposal involves the use of mobile devices for viewing different composite models that combine VR, AR, and DS Hybrid Models. In the final stage, a thorough collection of informal data from citizens who interacted with the students' 3D proposals has been done. A qualitative approach was also developed to asses both the formal and informal learning of the students in order gain a better comprehension of students and citizens opinion on the projects. Analyzing the results of these objectives will lead to a better understanding of how to implement new teaching methods with mobile technologies and how manage hybrid approaches between formal and informal education in our educational sector.

The need to identify and measure the public opinion of society is fundamental in all sorts of training and practice, especially if the recipient of the product is the citizen (Brooker, 2013). Their input can be transformed into new usable content in the education of any person, which has been defined as informal learning. Elections, protests, letters to editors, etc., are nothing more than ways of expression that allow citizens to share their opinion. Methods have been revolutionized with the rise of ICT: use of blogs, personal pages, movements' crowdfunding or support, etc. We can be certain that we are moving from Education Systems to Learning societies (CISCO, 2010), where the social, economic and environmental challenges of the 21 st century demand citizens with a broad perspective and the capacity and passion to engage with the world's problems both in their countries and abroad.

Focused on our case study, the space is the core of architecture, building and urban design. It is necessary to conceive and think about architectural space surrounding us by decoding its nature and discovering messages in its built forms. Critical questions arise at this point: How do architects, students and citizens perceive and conceptualize architectural space? How do all characters understand and decode space? How do they think and talk about space?

On the one hand, the students' results in the final assessment and the analysis of their final marks have demonstrated that by combining an attractive technology and user-machine interaction that involves $\mathrm{AR} / \mathrm{VR} / \mathrm{DS} / \mathrm{HM}$, students feel more motivated, have increased graphic competencies and spatial skills in shorter learning periods, and 
attain strongly improved academic performance. The results of the present study were in line with our assumptions that the use of mobile devices in the classroom, motivation, and academic achievement are highly correlated. However, the difficulty of generating content and the visualization of optimal models and details are complex factors that suggest some difficulties in implementing this technology in other subjects related to architectural education. The first objective of the proposal has been demonstrated once the results on the degree of motivation and formal appear. Following previous studies (see Section 2), it is clear that regardless of the sample (in our case very small), the involvement of the use of ICT for the development of real projects in educational fields generated positive feedback from students that resulted in better work and improved academic in results.

In a second stage, we have designed a first approach to recognize the informal learning that the citizenship can contribute in the education of architecture, building or urban design students. In this educational framework, the opinion of the end-user can help in the education and experience of the future urban planner or architect to avoid falling into typical errors as we have illustrated throughout the paper. The massive deployment of new technologies such as mobile type smartphone or tablets, increasing high-speed connections and free Wi-Fi, and new systems capable of linking additional information using two-dimensional codes are allowing citizens no longer users becoming liabilities 3.0 users: users with interactive capabilities to collaborate on the design and evaluation of the final products of any professional.

As seen in the results section, the information obtained informally has detected errors in the conceptualization of urban projects and other more specific errors of the studied proposals, such as the lack of exhibition space, the materials used, and their mobility, ete. Preliminary results (even using a small sample of citizens), demonstrate the importance of this type of informal interactions and how ICT helps in these processes. One of the most successful -and itself a challenge - aspects, has been the inclusion in the evaluation of groups usually excluded - in this case traders -. The feedback has been vital as the excellent formal proposals made "ex-ante" by students, received comments that suggested that if implemented would result in utter failures.

Without doubt, the incorporation of informal assessment into the student feedback is one of the key points (Cullen, Batterbury, Foresti, Lyons, \& Stern, 2000). As García-Peñalvo, Griffiths, Johnson, Sharples, and Sherlock (2014)state: “... a major barrier is observed when introducing such solutions in the day-to-day professional activities, and the validation of informal learning becomes an extension of the management processes of the formal educational processes ...". These professional and 
educational challenges shape a future where it is necessary to propose and evaluate methods for measuring informal responses in the curricular student records (European Guidelines, 2009; García-Peñalvo, Colomo-Palacios, \& Lytras, 2012). In this regard ICT is postulated as the ideal medium to drive this process (Hague, 2009); however we are still a long way from improving connectivity, cost and usability of devices and applications so that these methods are actually possible for citizens (both in developed and developing countries).

Probably, a good way to get the cooperation of citizens and increase their involvement into the informal field of education is through games. The gamification of any task not only leads to increased motivation of the participant, but allows a faster response of the user's opinion. In this sense, the designers of educational programs intended to incorporate the informal response into educational activities, need to pay attention when designing an interactive game so it is easy, usable, attractive, and allows citizens (our customers), to access it from various kinds of devices and at all times (García-Peñalvo, Johnson, Ribeiro Minovic \& Conde-González, 2014).

In conclusion, working with a collaborative interface, interactive discussions of all projects, and the capacity to generate physical and digital expositions are activities that have resulted in an active student, with significant improvements in spatial, research, and interaction skills. One of the highlights of the experience has been the change in perspective that was generated once the student was aware of how their work was perceived publicly. We can say that casual interactions obtained in the teaching methodology demonstrate how they can complement the knowledge and skills of students outside the established formal system. However their effective integration into the curriculum of the student remains challenging. In this sense the lack of control and monitoring, temporary programming and parameterization of the response in headings or quantifiable aspects work objectives for future projects or exercises to continue the experience described in this article are craving.

Likewise, AR technology applied in architecture, urban or building construction education offers an opportunity to visualize different stages of a constructive process "in situ", helping to improve the understanding of the process. This aspect allows the verification and comparison of different scenarios and virtual proposals prior to real construction. In addition, this technology could replace real interventions. To achieve this goal, it is important to study the ability to view different models with the same marker to show different layers, models, textures, and lighting. Furthermore, it will be necessary to establish systems that allow fluid exchanges between applications and the 
prevention of problems involving formats, versions, or loss of information, as occurred with colors and materials in the present study.

Finally, we would like to indicate that this educational research project falls under the Interest Group for Logistics and Teaching in Architecture (GILDA), an interuniversity group centered in the architectural framework assigned to the ICE (Institute of Education Sciences at the Polytechnic University of Catalonia - UPC), specialized in the field of teaching technology disciplines. The authors represent teachers of Visual Communication Architectural Graphic Expression Representation (EGAI/II) together with the "Informatics Tools"subjects of architecture at the Universidad Ramon Llull (URL) and usability experts in educational research. This project was made possible by the Fundamental Research Project Not Oriented of the VI National Plan for Scientific Research, Development and Technological Innovation 2008-2011, Government of Spain, $\mathrm{N}^{\circ}$ EDU-2012-37247/EDUC, titled: "E-learning 3.0 in the teaching of architecture. Case studies of educational research for the foreseeable future".

\section{References}

Al Shawa, B. (2011): The Darker Side of Villa Savoye. Misfits' Architecture. Retrieved 201412-10. <http://misfitsarchitecture.com/2011/09/03/the-darker-side-of-villa-savoye/>.

Banks, J., Au, K., Ball, A., Bell, P., Gordon, E., Gutierrez, K., \& Heath, S., et al. (2007). Learning in and out of school in diverse environments (Consensus Report), Learning in Informal and Formal Environment (LIFE) Center. Retrieved from $<$ http://www.ibparticipation.org/pdf/LearningInDiverseEnvironments.pdf $>$.

Bell P., et al., (Eds.), Learning science in informal environments: People, places, and pursuits, 2009, National Academies Press; Washington, DC.

Benévolo L., Historia de la Arquitectura moderna, 1997, Gustavo Gili; Barcelona.

Bennett S., Maton K. and Kervin L., The 'digital natives' debate: A critical review of the evidence, British Journal of Educational Technology 39, 2008,775786, http://dx.doi.org/10.1111/j.1467-8535.2007.00793.x.

Biggs J., What the student does: Teaching for enhanced learning, Higher Education Research \& Development 18 (1), 1999,57-75, <http://dx.doi.org/10.1080/0729436990180105>.

Bilandzic, M. (2013). Towards Hybrid Informal Learning Spaces: Designing for Digital Encounters in Physical Environments, PhD Final Seminar, 2013. $<$ http://es.slideshare.net/kavasmlikon/towards-hybrid-informal-learning-spacesdesigning-for-digital-encounters-in-physical-environments $>$. 
Binkley, M., Erstad, O., Herman, J., Raizen, S., Ripley, M. \& Rumble, M. (2011). Defining 21 st century skills. In P. Griffin, B. McGaw, \& E. Care (Eds.),Assessment and teaching of 21st century skills (pp. 17-66), New York: Springer.

Bobhate, P. (2011). Villa Savoye - An architectural wonder or a thermal disaster. In Proceedings of Conference: People and Buildings held at the offices of Arup UK, 23rd September 2011. London. Retrieved 2014-12-10. $<$ http://nceub.commoncense.info/uploads/MC2011_MC22.pdf $>$.

Boeykens, S., Santana-Quintero, M., \& Neuckermans, H. (2008). Improving Architectural Design Analysis using 3D Modeling and Visualization techniques. In M. Ioannides, A. Addison, A. Georgopoulos, \& L. Kalisperis (Eds.), Digital heritage: Proceedings of the 14th international conference on virtual systems and multimedia pages (pp. 67-73). Limassol, Cyprus.

Broll W., Lindt I., Ohlenburg J., Wittkämper M., Yuan C., Novotny T., et al.,ARTHUR: A collaborative augmented environment for architectural design and urban planning, Journal of Virtual Reality and Broadcasting 1 (1),2004, 102109, http://dx.doi.org/10.1080/0144929X.2012.661548.

Brooker, R. G. (2013). Public opinion in the 21st century draft, Alverno College Todd Schaefer, Central Washington University. Retrieved 14/04/2015: $<$ http://www.uky.edu/AS/PoliSci/Peffley/pdf/473Measuring\%20Public\%20Opinion.pdf $>$.

Chen R. and Wang X., An empirical study on tangible augmented reality learning space for design skill transfer, Tsinghua Science \& Technology 13, 2008,13-18.

CISCO (2010), The Learning Society, Retrieved 14/04/2015:

$<$ https://www.cisco.com/web/about/citizenship/socioeconomic/docs/LearningSociety_WhitePaper.pdf>.

Coombs P.H., Prosser C. and Ahmed M., New paths to learning for rural children and youth. International council for educational development, 1973, John Hopkins Press; New York.

Craven, J. (2013). Trouble in Paradise. The troubled story of the glass wallwd Farnsworth House. Retrieved 2014-12-15. $<$ http://tweedlandthegentlemansclub.blogspot.com.es/2013/05/trouble-in-paradisetroubled-story-of.html>.

Cullen, J., Batterbury, S., Foresti, M., Lyons, C., \& Stern, E. (2000). Informal learning and widening participation prepared for the department for education and employment. The 
Tavistock Institute. DfEE Research Report No. 191. Department for Education and Employment.

Dede C., Emerging influences of information technology on school curriculum,Journal of Curriculum Studies 32 (2), 2000, 282-303.

Di Serio Á., Ibáñez M.B. and Kloos C.D., Impact of an augmented reality system on students' motivation for a visual art course, Computers \& Education 2012, 1-11.

Dunleavy M., Dede C. and Mitchell R., Affordances and limitations of immersive participatory augmented reality simulations for teaching and learning,Journal of Science Education and Technology 18, 2008, 7-22.

European Guidelines (2009). European guidelines for validating non-formal and informal learning. European Centre for the Development of Vocational Training. Luxembourg: Office for Official Publications of the European Communities. p. 96.

Fonseca D., Martí N., Redondo E., Navarro I. and Sánchez A., Relationship between student profile, tool use, participation, and academic performance with the use of augmented reality technology for visualized architecture models, Computers in Human Behavior 31, 2014, 434-445,http://dx.doi.org/10.1016/j.chb.2013.03.006.

Foroughi B., Toronto community housing: Tenant participation and informal learning, The Canadian Journal for the Study of Adult Educational 25 (2),2013, 35-52.

Frampton K., Historia crítica de la Arquitectura moderna, 1981, Editorial GG;Barcelona.

Fraser, J., \& Miss, M. (2012). City as living laboratory for sustainability in urban design. New Knowledge Organization Ltd. Final Report, NewKnowledge Resource \#NSF2.5556.02, $24 \mathrm{p} .<\mathrm{http}: / /$ informalscience.org/images/evaluation/City_as_Living_Lab_Final_Report.p df $>$.

Fung A. and Wright E.O., Deepening democracy: Institutional innovations in empowered participatory governance, 2003, Verso; London.

García-Peñalvo F.J., Colomo-Palacios R. and Lytras M.D., Informal learning in work environments: Training with the Social Web in the workplace,Behaviour \& Information Technology 31 (8), 2012, 753-755,http://dx.doi.org/10.1080/0144929X.2012.661548.

García-Peñalvo F.J., Griffiths D., Johnson M., Sharples P. and Sherlock D.,Problems and opportunities in the use of technology to manage informal learning, In: GarcíaPeñalvo F.J., (Ed), Proceedings of the second international conference on technological ecosystems for enhancing multiculturality (TEEM'14), 2014, ACM; New York, USA, 573-580. 
García-Peñalvo F.J., Johnson M., Ribeiro Alves G., Minovic M. and Conde-

González M.Á., Informal learning recognition through a cloud ecosystem,Future

Generation Computer Systems 32, 2014, 282-

294,http://dx.doi.org/10.1016/j.future.2013.08.00.

Georgina D.A. and Olson M.R., Integration of technology in higher education: A review of faculty self-perceptions, Internet and Higher Education 11, 2007,1-

8, http://dx.doi.org/10.1016/j.iheduc.2007.11.002.

Gray S.A., Nicosia K. and Jordan R.C., Lessons learned from citizen science in the classroom.

A response to "The Future of Citizen Science", Democracy \&

Education 20 (2), 2012, 1-5.

Gschwandtner W.R. and Münzberger H., Lipoatrophia semicircularis. Ein Beitrag zu bandförmig-circulären Atrophien des subcutanen Fettgewebes im

Extremitätenbereich, Der Hautartz 25, 1974, 222-227.

Guidano V.F., Constructivist psychotherapy: A theoretical

framework, In:Neimeyer R.A. and Mahoney M.J., (Eds.), Constructivism in psychotherapy, 1989, Cambridge University Press; Cambridge.

Hague, C. (2009). General educators report, Learning Researcher, Futurelab, Educational Research Consultant

$<$ http://www2.futurelab.org.uk/resources/documents/project_reports/becta/Adult_Infor mal_Learning_educators_report.pdf $>$.

Hall B.L. and Clover D.E., Social movement learning, In: English L.M., (Ed),International encyclopedia of adult education, 2005, Palgrave Macmillan;New York, 584-589.

Harrop D. and Turpin B., A study exploring learners' informal learning space behaviors, attitudes, and preferences, New Review of Academic Librarianship 19 (1), 2013, 58-77.

Hawkinson, E. (2013). Informal learning environments in tourism: Interactive panoramas.

Tourism Institute of Northeast Asia International Academic Conference

2013 "Revitalization of Rural Experience

Tourism" $<$ https://www.academia.edu/7724215/Informal_Learning_Environments_in_T ourism_Augmented_Reality>.

Higueras, J. (2013). la Salle Open University, Scenario Centered Curriculum, el learning-bydoing de éxito en La Salle Open University, consultado 25 de julio de 2014.

$<$ http://blogs.uols.org/mba/scenario-centered-curriculum-el-learning-by-doing-de-exitoen-uols/>. 
Jamieson, P., Dane, J., \& Lippman, P. C. (2005). Moving beyond the classroom: Accommodating the changing pedagogy of higher education. Refereed Proceedings of 2005 Forum of the Australasian Association for Institutional Research (pp. 17-23).

Kreijns K., Acker F.V., Vermeulen M. and Buuren H.V., What stimulates teachers to integrate ICT in their pedagogical practices? The use of digital learning materials in education, Computers in Human Behavior 29, 2013, 217 225,http://dx.doi.org/10.1016/j.chb.2012.08.008.

Kristoffersen, S., \& Ljungberg, F. (1999). Mobile informatics innovation of IT use in mobile settings. In Proc. Of IRIS'21 workshop report. Special interest group on computer human interaction bulletin (Vol. 31(1), pp. 29-34).

Kuo Y.-F. and Yen S.-N., Towards an understanding of the behavioral intention to use 3G mobile valued-added services, Computers in Human Behavior 25 (1), 2009, 103110,http://dx.doi.org/10.1016/j.chb.2008.07.007.

La Belle J., Formal, nonformal and informal education: A holistic perspective on lifelong learning, International Review of Education 28 (2), 1982,159175, http://dx.doi.org/10.1007/BF00598444.

Lazzari M., Majowiecki M., Vitaliani R., Saetta A. and Nonlinear F.E., Analysis of montreal olympic stadium roof under natural loading conditions,Engineering Structures 31 (1), 2009, 1631,http://dx.doi.org/10.1016/j.engstruct.2008.07.010, (January, ISSN 0141-0296).

Leggitt J., Drawing shortcuts: Developing quick drawing skills using today’s technology, 2009, John Wiley \& Sons, 264.

Lehner, F., \& Nosekabel, H. (2002). The role of mobile devices in E with a wireless ELearning environment. In Proceedings of the IEEE international workshop on wireless and mobile technologies in education(pp. 103-106).

Lu Z., Learning with mobile technologies, handheld devices, and smart phones: Innovative methods, IGI-Global 2012, 1-272,http://dx.doi.org/10.4018/978-1-4666-0936-5.

Luna Corento, J. (2013): Fiascos arquitectónicos: los peligros del efecto Guggenheim. Retrieved 2014-12-15. <http://elarquitectohamuerto.blogspot.com.es/2013/12/fiascosarquitectonicos-efecto-guggenheim.html $>$.

Malawi, A., \& Srinivasan, R. (2004), Building performance visualization using augmented reality. In Proceedings of the fourteenth international conference on computer graphics and vision (pp. 122-127). 
Marsick, V. J., Watkins, K. E., Callahan, M. W., \& Volpe, M. (2006). Reviewing Theory and Research on Informal and Incidental Learning. Retrieved from ERIC on 2015-04-10 $<$ http://files.eric.ed.gov/fulltext/ED492754.pdf>.

Massy, W. F., \& Zemsky, R. (1995). Using information technology to enhance academic productivity. CAUSE Conference 1995. Available: $<$ http://www.educase.edu/nlii/keydocs/massy.html $>$.

Mateos, R. \& Quelart, R. (2014). La nueva baldosa de Barcelona, un suplicio para ir con tacones. Retrieved 2014-11-19. $<$ http://videos.lavanguardia.com/local/barcelona/20141119/54419992257/la-nuevabaldosa-de-barcelona-un-suplicio-para-ir-con-tacones.html>.

Medeiros, J. (2011). Educative Landscapes: Informal Learning and Landscape Architecture, Student ASLA <http://www.asla.org/ppn/Article.aspx?id=32161>.

Milgram, P., \& Takemura, H. (1994). Augmented reality: A class of displays on the realityvirtuality continuum. Presented at telemanipulator and telepresence technologies (Vol. 2351, pp. 282-292).

Moran, M., Seaman, J., \& Tinti-Kane, H. (2011). Teaching, Learning, and Sharing: How Today's Higher Education Faculty Use Social Media. Babson Survey Research Group.

Moreira, M. A., Santos, M. B. S. N., \& Vargas, E. F. (2010). Buenas prácticas de aulas virtuales en la docencia universitaria semipresencial. Teoría de la Educación: Educación y Cultura en la Sociedad de la Información, 11(1), 7-31.Mueller, M. P., Tippins, D., \& Bryan, L. A. The future of citizen science. Democracy \& Education, (2012). 20(1), (pp $1-12)$.

Nielsen, J. (2012). Usability 101: Introduction to usability, Jakob Nielsen's Alertbox. Retrieved 2010-06-01.

Nielsen, J. (2000). Norman, Donald A: Web-Site Usability: Usability. On the web isn't a luxury. informationweek.

Pampinella, S. (2000). Arquitecturas de autor o Arquitecturas de mecenas, en Revista Block n. 5, Buenos Aires.

Parsons D., Refining current practices in mobile and blended learning: New applications, IGIGlobal 2012, 1-334, http://dx.doi.org/10.4018/978-1-4666-0053-9.

Phang C.W. and Kankanhalli A., A framework of ICT exploitation for e-participation initiatives, Communications of the ACM 51, 2008, 128 132,http://dx.doi.org/10.1145/1409360.1409385, (December). 
Piekarski, W., \& Thomas, B. (2001). Tinmith-Metro: New outdoor techniques for creating city models with an augmented reality wearable computer. First International Symposium on Wearable Computers (ISWC '01) (pp. 31-38).

Pifarré, M., \& Tomico, O. (2007). Bipolar laddering (BLA): A participatory subjective exploration method on user experience. In Proceedings of the 2007 conference on designing for user eXperiences (DUX '07). ACM, New York, NY, USA, Article 2, doi: 10.1145/1389908.1389911.

Prensky M., Digital natives, digital immigrants Part 1, On the Horizon 9 (5),2001, 1-6.

Redondo, E. (2010). Dibujo digital: hacia una nueva metodología docente para el dibujo arquitectónico: un estudio de caso. Revista Pixel-Bit. Revista de Medios y Educación. In $<$ http://www.sav.us.es/pixelbit/actual/7.pdf $>$.

Redondo E. and Santana G., Teaching methodologies based on touch interfaces for the teaching of drawing and architectural projects,Arquiteturarevista 6 (2), 2010, 90105,http://dx.doi.org/10.4013/arq.2010.62.02.

Retalis S. and Sloep P., B virtual environments for collaborative innovation and learning J UCS special issue, Journal of Universal Computer Science 17 (12), 2011, 1634-1637.

Rios, M. (2014). Learning from informal practices: Implications for urban design. $<$ https://www.academia.edu/8143136/Learning_from_Informal_Practices_Implications _for_Urban_Design> (173-191, Chapter 9).

Roca J. and Gagné M., Understanding e-learning continuance intention in the workplace. A self-determination theory perspective, Computers in Human Behavior 24, 2008, 1585 1604,http://dx.doi.org/10.1016/j.chb.2007.06.001.

Rodriguez-Izquierdo R.M., El impacto de las TIC en la transformación de la enseñanza universitaria: repensar los modelos de enseñanza y aprendizaje, Teoría de la Educación, Educación y Cultura en la Sociedad de la Información 11 (3), 2010, 32-68.

Rogers D.L., A paradigm shift: Technology integration for higher education in the new millennium, Educational Technology Review 2000, 19-33.

Romanillos, T. (2007). Lipoatrodia semicircular, La enfermedad de los nuevos edificios de oficinas. Retrieved 2014-12-12. $<$ http://www.consumer.es/web/es/salud/problemas_de_salud/2007/04/27/162011.php>.

Roult R. and Lefebvre S., Planning and reconversion of olympic heritages: The montreal olympic stadium, The International Journal of the History of Sport 27 (1618), 2010, 2731-2747. 
Sánchez, J. R., \& Borro, D. (2007). Automatic augemeted video creation for markerless environments. In Poster proceedings of the 2nd international conference on computer vision theory and applications (VISAPP' 07) (pp. 519-522).

Sánchez, A., Redondo, E., \& Fonseca, D. (2012). Developing an augmented reality application in the framework of architecture degree. In Proceedings of the ACM workshop on User experience in e-learning and augmented technologies in education (UXeLATE '12) (pp. 37-42). ACM, New York, NY, USA, doi: $<10.1145 / 2390895.2390905>$.

Scheerens, J. (2009). Informal learning of active citizenship at school. An international comparative study in seven european countries series: Lifelong learning book series, Vol. 14. In Scheerens, Jaap (Ed.), XII, 370p. Springer Science + Business Media B.V., doi: 10.1007/978-1-4020-9621-1_1.

Schugurensky, D., \& Myers, J. P. (2008). Informal Civic Learning Through Engagement in Local Democracy: The Case of the Seniors' Task Force of Healthy City Toronto. Learning through Community: Exploring Participatory Practices. K. Church et al. (eds.), Springer Science + Business Media B.V. (pp. 73-95, Chapter 5).

Schugurensky D., The tango of citizenship learning and participatory democracy,In: Mundel K. and Schugurensky D., (Eds.), Lifelong citizenship learning, participatory democracy and social change, 2004, Transformative Learning Centre, OISE/University of Toronto; Toronto, 326-334.

Shen C.X., Liu R.D. and Wang D., Why are children attracted to the Internet? The role of need satisfaction perceived online and perceived in daily real life, Computers in Human Behavior 29 (1), 2013, 185-192,http://dx.doi.org/10.1016/j.chb.2012.08.004.

Shin D.H. and Dunston P.S., Identification of application areas for Augmented Reality in industrial construction based on technology suitability,Automation in Construction 17 (7), 2008, 882-894.

Sully, N. (2009). Moder Architecture and Complaints about the Weather, or, 'Dear Monsieur Le Corbusier, it is still raining in our garage.”. M/C Journal 12(4). Retrieved 2014-1210. $<$ http://journal.media-culture.org.au/index.php/mcjournal/article/viewArticle/172>.

Taylor-Foster, J. (2013). Los siete pecados arquitectónicos cometidos alrededor del mundo. Retrieved 2014-12-15. <http://www.plataformaarquitectura.cl/cl/02-291775/sieteerrores-arquitectonicos-cometidos-alrededor-del-mundo $>$. 
Tonn C., Petzold F., Bimber O., Grundhöfer A. and Donath D., Spatial augmented reality for architecture designing and planning with and within existing buildings, International Journal of Architectural Computing 6 (1), 2008,41-58.

Uddin M.S., Hybrid drawing techniques by contemporary architects and designers, 1999, John Wiley \& Sons; New York.

Villagrasa, S., Fonseca, D., \& Durán, J. (2014). Teaching case: Applying gamification techniques and virtual reality for learning building engineering 3D arts. In Proceedings of the second international conference on technological ecosystems for enhancing multiculturality (pp. 171-177). ACM (October).

Werquin P., Recognition of non-formal and informal learning in OECD countries: A very good idea in jeopardy?, Lifelong Learning in Europe 3, 2008, 142-149.

Wood, L. C., Teräs, H., \& Reiners, T. (2013). The role of gamification and game-based learning in authentic assessment within virtual environments, held at AUT University, Auckland, New Zealand, 2013-07-01 to 2013-07-04 Publisher: Higher Education Research and Development Society of Australasia (HERDSA)].

Wright G., The political economy of the montreal olympic games, Journal of Sport \& Social Issues 2, 1978, 13-18,http://dx.doi.org/10.1177/019372357800200103), (March).

Yaman R., Architectural design representation: The hybrid drawing, Built Environment Journal 6 (2), 2009, 25-40 